\title{
Hyperbranched polyethyleneimine induced polycationic membranes for improved fouling resistance and high RO performance
}

\author{
Aneela Sabir ${ }^{\text {a,c,*}}$, Wail Falath ${ }^{\text {a,d }}$, Karl I. Jacob ${ }^{\text {a,b }}$, Muhammad Shafiq ${ }^{\text {c, }}$ \\ Muhammad Azeem Munawar ${ }^{c}$, Atif Islam ${ }^{c}$, Nafisa Gull ${ }^{a}$, Muhammad Taqi Zahid Butt ${ }^{\mathrm{e}}$, \\ Khairuddin Sanaullah ${ }^{\mathrm{f}}$, Tahir Jamil ${ }^{\mathrm{c}}$ \\ a School of Materials Science and Engineering, Georgia Institute of Technology, Atlanta, GA, USA \\ ${ }^{\mathrm{b}}$ G.W. Woodruff School of Mechanical Engineering, Georgia Institute of Technology, Atlanta, GA, USA \\ ${ }^{\mathrm{c}}$ Department of Polymer Engineering and Technology, University of the Punjab, Lahore 54590, Pakistan \\ ${ }^{\mathrm{d}}$ Department of Mechanical Engineering, King Fahd University of Petroleum and Minerals, Dhahran 31261, Saudi Arabia \\ ${ }^{\mathrm{e}}$ Faculty of Engineering and Technology, University of the Punjab, Lahore 54590, Pakistan \\ ${ }^{\mathrm{f}}$ Department of Chemical Engineering and Energy Sustainability, Faculty of Engineering, Universiti Malaysia Sarawak (UNIMAS) 94300 Kota Samarahan, \\ Sarawak, Malaysia
}

\section{A R T I C L E I N F O}

\section{Article history:}

Received 12 August 2016

Received in revised form 15 October 2016

Accepted 20 October 2016

Available online 21 October 2016

\section{Keywords:}

Antifouling

Membrane

Reverse osmosis

Natural sea salt

\begin{abstract}
A B S T R A C T
The study shows a new method for hyperbranched polyethyleneimine (HPEI) induced polycation membranes with an objective of achieving better fouling resistance and high reverse osmosis (RO) performance. Chemically crosslinked composite membrane (CCCM) was prepared with polyvinyl alcohol (PVA), maleic acid (MA) and Pluronic F127 via chemical crosslinking methodology. Polycation induced membranes were fabricated by surface coating of HPEI onto the CCCM (PVA/MA/PluronicF127) RO membranes. Functional group analysis, morphology and surface roughness of CCCM and HPEI-RO membranes were analyzed by Fourier transform infrared spectroscopy, scanning electron microscopy and atomic force microscopy respectively. The hydrophilicity and water permeability of CCCM and HPEI-RO were examined with water contact angle measurement and RO performance test. Optimum RO performance was obtained for HPEI-RO3 membrane with $\mathrm{NaCl}$ and $\mathrm{MgSO}_{4}$, as for $\mathrm{R}_{\mathrm{NaCl}}=96.1 \%, \mathrm{~J}_{\mathrm{NaCl}}=58.2 \mathrm{~L} \mathrm{~m}^{-2} \mathrm{~h}^{-1}$ and $\mathrm{R}_{\mathrm{MgSO} 4}=99.6 \%$, $\mathrm{J}_{\mathrm{MgSO} 4}=15.8 \mathrm{~L} \mathrm{~m}^{-2} \mathrm{~h}^{-1}$ (testing with 3.28 wt.\% aqueous $\mathrm{NaCl}$ and $\mathrm{MgSO}_{4}$ solution at $25{ }^{\circ} \mathrm{C}$ and 55 bar). Moreover, cetyl trimethylammonium bromide (CTAB) as standard foulants presented a smaller fouling tendency for the modified HPEI-RO3 membrane. HPEI-RO3 compared to the unmodified membrane, was able to decrease the stickiness of charged bacteria, Gram negative Escherichia coli and Gram positive Staphylococcus epidermidis. Therefore, the permeation flux, salt rejection and fouling resistant property of membrane (HPEI-RO3) were significantly improved with polycation induction into the membranes.
\end{abstract}

(c) 2016 Elsevier Ltd. All rights reserved.

\footnotetext{
* Corresponding author at: School of Materials Science and Engineering, Georgia Institute of Technology, Atlanta, GA, USA.

E-mail addresses: aneela.pet.ceet@pu.edu.pk (A. Sabir), tahirj4@yahoo.com (T. Jamil).
} 